\title{
Effects of phosphorus fertilizer on growth, yield and quality of coconut at early reproductive stage under saline intrusion condition in Mekong Delta
}

Tri D. H. Nguyen ${ }^{1 *}$, Nong C. Le ${ }^{1}$, Thu N. Q. Thai ${ }^{1}$, Thang Q. Luu ${ }^{1}, \&$ Chuong D. X. Nguyen ${ }^{2}$

${ }^{1}$ Research Institute for Oil and Oil Plants, Ho Chi Minh City, Vietnam

${ }^{2}$ Faculty of Agronomy, Nong Lam University, Ho Chi Minh City, Vietnam

ARTICLE INFO
Research Paper
Received: July 26, 2020
Revised: August 17, 2020
Accepted: August 26, 2020
Keywords
Coconut tree
Mekong Delta
Phosphorus fertilizer
Saline intrusion
*Corresponding author
Nguyen Doan Huu Tri
Email: huutri1207@gmail.com

\begin{abstract}
Coconut palm (Cocos nucifera L.) is one of the most important oil crops in the tropics. The tree is able to grow well under saline intrusion condition. However, in the case of high level of salinity for a long period, the coconut tree is severely affected, resulting in poor growth and yield. Therefore, providing balance and sufficient nutrients would help plants tolerate better to unsuitable environment including salinity. Among plant macronutrients, phosphorus is considered to help coconut tree have more roots and leaves, stimulating flowers formation and fruit setting which lead to improve yields. The aim of this work was to determine effects of the amount of phosphorus fertilizer and the frequency of application on growth, yield and quality of coconut tree at early reproductive stage under saline intrusion condition. Two two-factor experiments were conducted in Binh Dai district, Ben Tre province and Tan Phu Dong district, Tien Giang province where the highest salinity in the dry season reached $13.8 \% 0$ and $6.3 \%$, respectively. The treatments of experiments were arranged in split-plot design (SPD) with three replications. The main plot factor was the frequency of phosphorus fertilizer application (2 and 4 times per year) and the sub-plot factor was the amount of phosphorus fertilizer $\left(30,45,60\right.$ and $75 \mathrm{~kg} \mathrm{P}_{2} \mathrm{O}_{5} / \mathrm{ha} /$ year $)$. The results showed that coconut trees grew best with the treatment of four applications of 60 $\mathrm{kg} \mathrm{P}_{2} \mathrm{O}_{5} / \mathrm{ha} /$ year, corresponding to $0.3 \mathrm{~kg} \mathrm{P}_{2} \mathrm{O}_{5} /$ tree/year. The trees in this treatment had more leaves, fruit setting, nut number per tree and higher yield than other treatments under saline intrusion condition.
\end{abstract}

Cited as: Nguyen, T. D. H., Le, N. C., Thai, T. N. Q., Luu, T. Q., \& Nguyen, C. D. X. (2020). Effects of phosphorus fertilizer on growth, yield and quality of coconut at early reproductive stage under saline intrusion condition in Mekong Delta. The Journal of Agriculture and Development $19(4), 18-27$. 


\title{
Ảnh hưởng của phân lân đến sinh trưởng, năng suất và chất lượng dừa ở đầu giai đoạn kinh doanh trong điều kiện xâm nhập mặn tại đồng bằng sông Cửu Long
}

\author{
Nguyễn Đoàn Hữu Trí ${ }^{1 *}$, Lê Công Nông ${ }^{1}$, Thái Nguyễn Quỳnh Thư ${ }^{1}$, \\ Lưu Quốc Thắng ${ }^{1}$ \& Nguyễn Đức Xuân Chương ${ }^{2}$ \\ ${ }^{1}$ Viện Nghiên Cứu Dầu và Cây Có Dầu, TP. Hồ Chí Minh \\ ${ }^{2}$ Khoa Nông Học, Trường Đại Học Nông Lâm TP.HCM, TP. Hồ Chí Minh
}

\section{THÔNG TIN BÀI BÁO}

Bài báo khoa học

Ngày nhận: 26/07/2020

Ngày chỉnh sửa: $17 / 08 / 2020$

Ngày chấp nhận: 26/08/2020

\section{Từ khóa}

Cây dừa

Đồng bằng sông Cửu Long

Phân lân

Xâm nhập mặn

\section{*Tác giả liên hệ}

Nguyễn Đoàn Hữu Trí

Email: huutri1207@gmail.com

\section{TÓM TẮT}

Cây dừa (Cocos nucifera L.) là một trong những cây trồng lấy dầu quan trọng ở các vùng nhiệt đới. Cây dừa có khả năng sinh trưởng tốt trong điều kiện xâm nhập mặn. Tuy nhiên, nếu xâm nhập mặn cao và kéo dài, cây dừa sẽ bị ảnh hưởng nghiêm trọng, sinh trưởng chậm và cho năng suất kém. Vì thế, cung cấp cân bằng và đầy đủ chất dinh dưỡng sẽ giúp cây dừa tăng khả năng chống chịu ở các điều kiện bất lợi, trong đó có xâm nhập mặn. Trong các loại dinh dưỡng đa lượng, lân giúp cho cây dừa ra rễ tốt và tăng trưởng số lá, kích thích ra hoa và tăng tỉ lệ đậu trái, qua đó cải thiện năng suất. Vì vậy, nghiên cứu được tiến hành nhằm xác định số lần bón và liều lượng phân lân đến sinh trưởng, năng suất cây dừa và chất lượng trái dừa ở giai đoạn đầu kinh doanh trong điều kiện xâm nhập mặn. Hai thí nghiệm hai yếu tố được thực hiện tại huyện Bình Đại, tỉnh Bến Tre và huyện Tân Phú Đông, tỉnh Tiền Giang, có độ mặn cao nhất vào mùa khô lần lượt là $13,8 \%$ và $6,3 \%$. Thí nghiệm được bố trí theo kiểu lô phụ với 3 lần lặp lại. Yếu tố chính là số lần bón (2 và 4 lần/năm) và yếu tố phụ là liều lượng phân lân $(30$, 45, 60 và $75 \mathrm{~kg} \mathrm{P}_{2} \mathrm{O}_{5} / \mathrm{ha} /$ năm). Kết quả cho thấy cây dừa sinh trưởng tốt nhất ở nghiệm thức bón 4 lần/năm với $60 \mathrm{~kg} \mathrm{P}_{2} \mathrm{O}_{5} / \mathrm{ha} / \mathrm{năm}$, tương ứng với $0,3 \mathrm{~kg} \mathrm{P}_{2} \mathrm{O}_{5} /$ cây/năm. Cây dừa ở nghiệm thức này có số lá mọc thêm, tỉ lệ đậu trái, số trái/cây và năng suất cao hơn so với các nghiệm thức còn lại trong điều kiện xâm nhập mặn.

\section{1. Đặt Vấn Đề}

Cây dừa (Cocos nucifera L.) là loại cây lấy dầu được trồng phổ biến ở vùng nhiệt đới trên thế giới (Nguyen \& ctv., 2005). Với nhiều giá trị dinh dưỡng và công dụng, cây dừa có vị trí quan trọng trong cơ cấu cây trồng của các nước khu vực nhiệt đới. Tính đến cuối năm 2018, tổng diện tích trồng dừa trên toàn thế giới là 12.303 .924 ha, đạt sản lượng 60.773.435 tấn (FAO, 2020). Nhu cầu tiêu thụ các sản phẩm tươi đến chế biến từ cây dừa được dự báo sẽ tăng cao trong tương lai. Cây dừa có nhiều giá trị kinh tế, tuy không cao so với các cây ăn trái hay công nghiệp lâu năm khác nhưng có tính ổn định về thị trường và bền vững về môi trường sinh thái (Cheng, 2011). Tuy nhiên, trong tình hình biến đổi khí hậu, khả năng nhiễm mặn được dự báo ngày càng cao, ảnh hưởng nghiêm trọng tới sản xuất cây trồng nói chung và canh tác cây dừa nói riêng. Theo Thai \& ctv. (2018), cây dừa có khả năng chịu mặn cao lên đến 10\%o, nhưng thực tế cho thấy tại đồng bằng sông Cửu Long xâm nhập mặn ở mức cao và kéo dài dẫn đến khả năng sinh trưởng và năng suất của cây dừa giảm đi, trong đó ảnh hưởng nhiều nhất tại một số vùng điển hình như Bình Đại, Thạnh Phú, 
tỉnh Bến Tre và Tân Phú Đông, tỉnh Tiền Giang. Theo BTSO (2018), sản lượng dừa của Bến Tre năm 2018 giảm từ 50 đến $60 \%$ so với năm 2017 do ảnh hưởng của xâm nhập mặn.

Cây dừa có đặc tính sinh trưởng liên tục và ra hoa đậu trái quanh năm, do đó nếu được bón phân nhiều lần trong năm cây sẽ sinh trưởng tốt, ra hoa liên tục, tăng số phát hoa và cải thiện năng suất. Cùng một lượng phân bón, nếu được chia bón nhiều lần sẽ giúp cây hấp thụ hiệu quả hơn và tránh được sự thất thoát (Tran \& Nguyen, 2011). Trong các loại phân bón, phân lân tác động nhiều đến quá trình kích thích ra rễ, thúc đẩy sinh trưởng và phân hóa mầm hoa, qua đó giúp cây dừa tăng số phát hoa, số hoa cái, tỉ lệ thụ phấn thụ tinh, sự hình thành và nâng cao chất lượng trái. Theo Nguyen \& ctv. (2005), phân lân giúp bộ rễ của cây dừa phát triển mạnh, cây hấp thu các chất dinh dưỡng trong đất tốt hơn và tạo điều kiện cho cây dừa ra hoa sớm ở thời kỳ đầu giai đoạn kinh doanh. Các nghiên cứu cho thấy, trên vùng đất nhiễm mặn, liều lượng phân lân thích hợp cho cây dừa Ta ở thời kỳ đầu giai đoạn kinh doanh từ 30 dến $40 \mathrm{~kg} \mathrm{P} \mathrm{P}_{2} \mathrm{O}_{5} / \mathrm{ha} /$ năm (Nguyen \& ctv., 2005; Pham \& ctv., 2010; Thai \& ctv., 2015). Tại đồng bằng sông Cửu Long, liều lượng phân lân bón cho cây dừa của nông dân ở mức $48 \mathrm{~kg}$ $\mathrm{P}_{2} \mathrm{O}_{5} /$ ha/năm trong thời kỳ cho trái ở mô hình chuyên canh dừa Ta theo kết quả điều tra của Tran \& Trieu (2011). Phân lân có vai trò quan trọng đối với cây dừa, nếu bị thiếu hụt có thể làm giảm sự sinh trưởng và năng suất cây đáng kể nhưng nếu thừa lân sẽ dẫn đến trái dừa chín sinh lý chậm và khối lượng cơm dừa khô giảm (Ton, 1974). Vì vậy, nghiên cứu này đã được thực hiện nhằm xác định số lần bón và liều lượng phân lân thích hợp cho sinh trưởng, năng suất và chất lượng cây dừa trồng tại vùng đất nhiễm mặn tại Bến Tre và Tiền Giang.

\section{Vật Liệu và Phương Pháp Nghiên Cứu}

\subsection{Vật liệu thí nghiệm}

Giống dừa Ta được Viện Nghiên cứu Dầu và Cây có dầu tuyển chọn trong điều kiện nhiễm mặn. Vườn dừa thí nghiệm có 5 năm tuổi, đang bắt đầu cho trái và các cây thí nghiệm có độ đồng đều. Phân bón sử dụng là phân lân nung chảy Ninh Bình, gồm có $15 \% \mathrm{P}_{2} \mathrm{O}_{5}, 28 \% \mathrm{CaO}$, $14 \% \mathrm{MgO}, 0,0012 \% \mathrm{Cd}$ và có độ ẩm là $1 \%$.

\subsection{Bố trí thí nghiệm}

Thí nghiệm được bố trí theo kiểu lô phụ (SPD) gồm có 08 nghiệm thức và 03 lần lặp lại, yếu tố lô chính là số lần bón (2 và 4 lần/năm), yếu tố lô phụ là liều lượng phân lân $(30,45,60$ và $75 \mathrm{~kg}$ $\mathrm{P}_{2} \mathrm{O}_{5} / \mathrm{ha} /$ năm) trên nền phân bón $320 \mathrm{~kg}$ Komix + $90 \mathrm{~kg} \mathrm{~N}+130 \mathrm{~kg} \mathrm{~K}{ }_{2} \mathrm{O}$ cho ha/năm.

Thí nghiệm được thực hiện tại xã Bình Thới, huyện Bình Đại, tỉnh Bến Tre và xã Tân Phú, huyện Tân Phú Đông, tỉnh Tiền Giang từ tháng $3 / 2019$ đến $6 / 2020$, trên hai vùng đất có hàm lượng dinh dưỡng thấp (Bảng 1 ) và độ mặn cao nhất của nước trong mương vườn dừa vào mùa khô tại Bến Tre là 13,8\%o và 6,3\%o tại Tiền Giang (Hình 1).

Hàm lượng dinh dưỡng trong đất và trong lá dừa trước khi thí nghiệm trình bày ở Bảng 1 và Bảng 2.

Theo phương pháp của Santos \& ctv. (1996) và IRHO (1992) với các chỉ tiêu theo dõi sau:

- Sinh trưởng: tổng số lá mọc thêm (lá) và chiều dài phần mang lá của lá chức năng $(\mathrm{cm})$. Lá chức năng được xác định từ lá chưa mở đến lá vị trí thứ 14 từ trên xuống theo hình xoáy ốc.

- Năng suất: tî̉ lệ đậu trái (\%), số trái/buồng (trái) và năng suất thực thu (trái/7 tháng) tính đến thời điểm kết thúc thí nghiệm.

- Chất lượng trái: khối lượng trái (g), khối lượng cơm $(\mathrm{g})$ và hàm lượng dầu $(\%)$ (xác định hàm lượng dầu theo phương pháp thử AOCS Aa4-38).

- Hàm lượng dinh dưỡng và chất hữu cơ trong đất trước và sau thí nghiệm: $\mathrm{N}$ dễ tiêu (phương pháp thử TCVN 5255:2009), P dễ tiêu (phương pháp thử TCVN 5256:2009), K trao đổi (phương pháp thử TCVN 8662:2011) và chất hữu cơ (phương pháp thử TCVN 8941:2011).

- Hàm lượng dinh dưỡng trong lá chức năng trước và sau thí nghiệm: nitơ (phương pháp thử 10 TCN 451:2001), photpho (phương pháp thử 10 TCN 453:2001) và kali (phương pháp thử 10 TCN 454:2001).

- Đo pH và Ec của mẫu đất các nghiệm thức sau khi kết thúc thí nghiệm bằng máy đo Hanna HI 2550.

Xử lý số liệu: số liệu thu thập, tổng hợp bằng phần mềm Excel và xử lý thống kê bằng phần mềm SAS 9.1. 
Bảng 1. Hàm lượng dinh dưỡng trong đất trước thí nghiệm tại huyện Bình Đại, tỉnh Bến Tre và huyện Tân Phú Đông, tỉnh Tiền Giang

\begin{tabular}{cccc}
\hline Chỉ tiêu & Đơn vị & Bình Đại & Tân Phú Đông \\
\hline N dễ tiêu & $\mathrm{mg} / 100 \mathrm{~g}$ dất & 1,40 & 1,90 \\
$\mathrm{P}$ dễ tiêu & $\mathrm{mg} / 100 \mathrm{~g}$ dất & 9,10 & 9,50 \\
K trao đổi & $\mathrm{mg} / 100 \mathrm{~g}$ dất & 31,30 & 33,90 \\
Chất hữu cơ & $\%$ & 1,90 & 3,40 \\
$\mathrm{pH}$ & - & 4,7 & 4,5 \\
Ec & $\mathrm{mS} / \mathrm{cm}$ & 0,42 & 0,18 \\
\hline
\end{tabular}

Bảng 2. Hàm lượng dinh dưỡng trong lá dừa trước thí nghiệm tại huyện Bình Đại, tỉnh Bến Tre và huyện Tân Phú Đông, tỉnh Tiền Giang

\begin{tabular}{cccc}
\hline Chỉ tiêu & Đơn vị & Bình Đại & Tân Phú Đông \\
\hline $\mathrm{N}$ tổng & $\%$ & 1,50 & 1,60 \\
$\mathrm{P}$ tổng & $\%$ & 0,08 & 0,09 \\
$\mathrm{~K}$ tổng & $\%$ & 0,80 & 0,97 \\
\hline
\end{tabular}

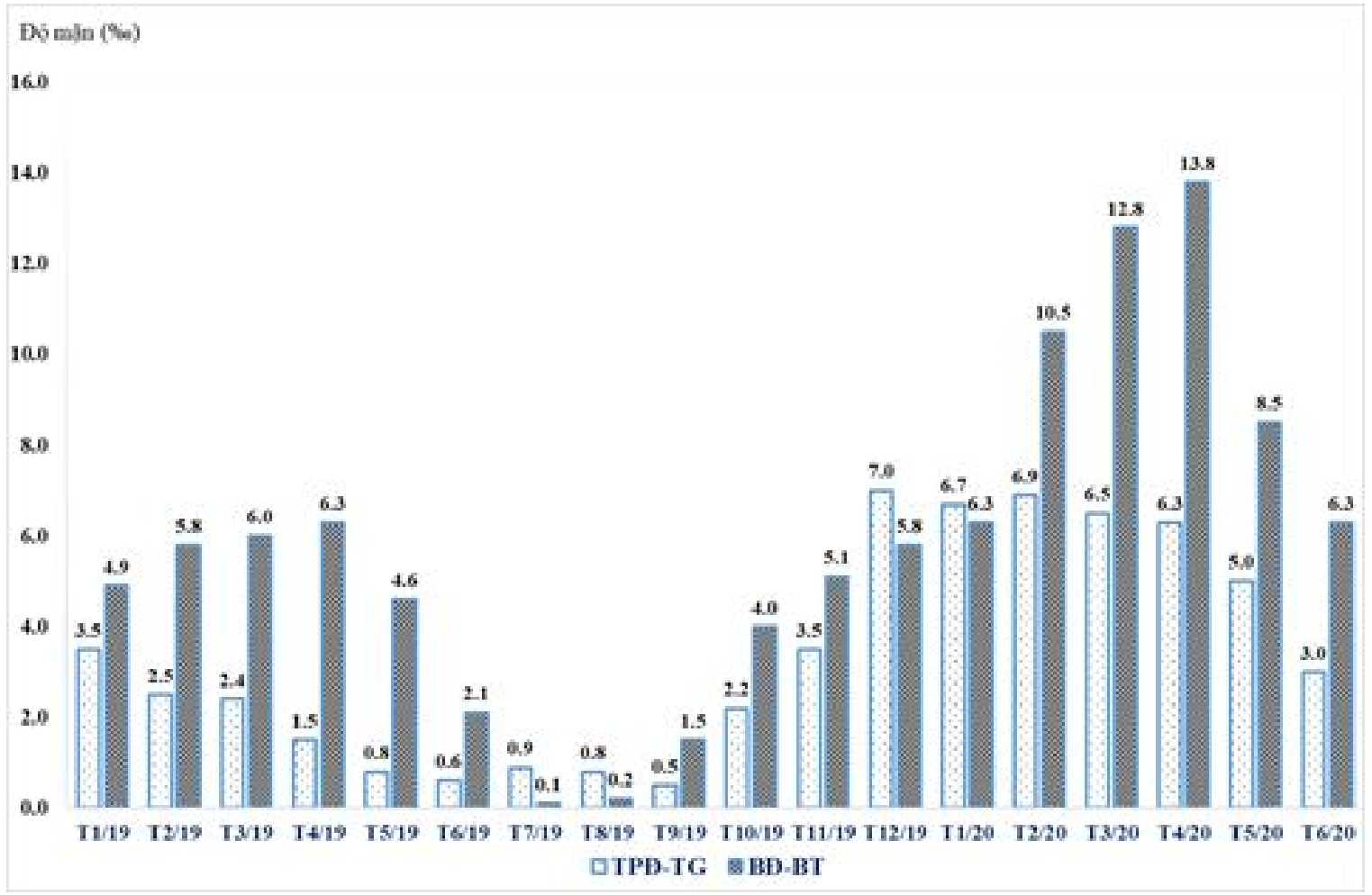

Hình 1. Diễn biến độ mặn tại Bến Tre và Tiền Giang từ tháng 1/2019 đến 6/2020.

\section{Kết Quả và Thảo Luận}

\subsection{Hàm lượng dinh dưỡng trong đất và trong lá dừa sau thí nghiệm}

Bảng 3 và 4 cho thấy hàm lượng dinh dưỡng trong đất sau thí nghiệm tại Bến Tre và Tiền
Giang đều tăng lên, trong đó với cùng một lượng phân lân, hàm lượng lân ở các nghiệm thức bón 4 lần/năm cao hơn các nghiệm thức bón 2 lần/năm, điều này cho thấy khi số lần bón tăng lên, phân bón ít bị rửa trôi và hiệu suất sử dụng phân bón cao hơn. Qua đó, độ $\mathrm{pH}$ của các nghiệm thức được cải thiện, tăng từ đến 0,48 đến 0,52 tại Bến 
Bảng 3. Hàm lượng dinh dưỡng trong đất sau thí nghiệm tại huyện Bình Đại, tỉnh Bến Tre

\begin{tabular}{cccccccccc}
\hline \multirow{2}{*}{ Chỉ tiêu } & \multirow{2}{*}{ Đơn vị } & \multicolumn{6}{c}{ Nghiệm thức (số lần bón/liều lượng phân lân) (\#) } \\
\cline { 3 - 10 } & & $2 / 30$ & $2 / 45$ & $2 / 60$ & $2 / 75$ & $4 / 30$ & $4 / 45$ & $4 / 60$ & $4 / 75$ \\
\hline N dễ tiêu & $\mathrm{mg} / 100$ g dất & 3,2 & 3,5 & 3,9 & 3,8 & 3,7 & 3,9 & 4,1 & 4,2 \\
P dễ tiêu & $\mathrm{mg} / 100 \mathrm{~g}$ dất & 12,1 & 12,3 & 12,5 & 12,7 & 12,6 & 12,8 & 13,5 & 14,1 \\
K trao đổi & $\mathrm{mg} / 100 \mathrm{~g}$ dất & 32,6 & 32,1 & 32,4 & 32,8 & 32,8 & 33,2 & 33,1 & 34,2 \\
Hữu cơ & $\%$ & 2,2 & 2,1 & 2,1 & 2,1 & 2,3 & 2,3 & 2,3 & 2,4 \\
pH & - & 5,2 & 5,1 & 5,2 & 5,2 & 5,2 & 5,1 & 5,2 & 5,1 \\
Ec & $\mathrm{mS} / \mathrm{cm}$ & 0,82 & 0,83 & 0,82 & 0,81 & 0,80 & 0,83 & 0,82 & 0,83 \\
\hline
\end{tabular}

(\#) Số lần bón: lần/năm; liều lượng phân lân: $\mathrm{kg} \mathrm{P}_{2} \mathrm{O}_{5} / \mathrm{ha} /$ năm.

Bảng 4. Hàm lượng dinh dưỡng trong đất sau thí nghiệm tại huyện Tân Phú Đông, tỉnh Tiền Giang

\begin{tabular}{cccccccccc}
\hline \multirow{2}{*}{ Chỉ tiêu } & \multirow{2}{*}{ Đơn vị } & \multicolumn{7}{c}{ Nghiệm thức (số lần bón/liều lượng phân lân) ${ }^{(\#)}$} \\
\cline { 3 - 10 } & & $2 / 30$ & $2 / 45$ & $2 / 60$ & $2 / 75$ & $4 / 30$ & $4 / 45$ & $4 / 60$ & $4 / 75$ \\
\hline N dễ tiêu & $\mathrm{mg} / 100 \mathrm{~g}$ dất & 5,4 & 5,5 & 5,3 & 5,3 & 6,0 & 5,8 & 5,4 & 5,5 \\
P dễ tiêu & $\mathrm{mg} / 100 \mathrm{~g}$ dất & 11,3 & 11,5 & 13,8 & 14,5 & 12,1 & 12,4 & 14,2 & 14,7 \\
K trao đổi & $\mathrm{mg} / 100$ g dất & 35,2 & 36,6 & 35,4 & 36,1 & 38,1 & 37,9 & 36,8 & 38,1 \\
Hữu cơ & $\%$ & 3,5 & 3,7 & 3,9 & 3,6 & 3,6 & 4,1 & 4,2 & 4,3 \\
pH & - & 5,0 & 5,0 & 5,0 & 4,9 & 4,9 & 4,9 & 5,0 & 4,9 \\
Ec & $\mathrm{mS} / \mathrm{cm}$ & 0,63 & 0,60 & 0,62 & 0,62 & 0,61 & 0,63 & 0,63 & 0,62 \\
\hline
\end{tabular}

(\#) Số lần bón: lần/năm; liều lượng phân lân: $\mathrm{kg} \mathrm{P}_{2} \mathrm{O}_{5} / \mathrm{ha} /$ năm.

Bảng 5. Hàm lượng dinh dưỡng trong lá sau thí nghiệm tại huyện Bình Đại, tỉnh Bến Tre

\begin{tabular}{|c|c|c|c|c|c|c|c|c|c|}
\hline \multirow{2}{*}{ Chỉ tiêu } & \multirow{2}{*}{ Đơn vị } & \multicolumn{8}{|c|}{ Nghiệm thức (số lần bón/liều lượng phân lân)(\#) } \\
\hline & & $2 / 30$ & $2 / 45$ & $2 / 60$ & $2 / 75$ & $4 / 30$ & $4 / 45$ & $4 / 60$ & $4 / 75$ \\
\hline $\mathrm{N}$ & $\%$ & 1,59 & 1,6 & 1,63 & 1,64 & 1,6 & 1,66 & 1,75 & 1,73 \\
\hline $\mathrm{P}$ & $\mathrm{mg} / \mathrm{kg}$ & 805 & 815 & 842 & 835 & 820 & 830 & 858 & 847 \\
\hline K & $\%$ & 0,85 & 0,86 & 0,91 & 0,90 & 0,86 & 0,93 & 1,00 & 0,94 \\
\hline
\end{tabular}

(\#) Số lần bón: lần/năm; liều lượng phân lân: $\mathrm{kg} \mathrm{P}_{2} \mathrm{O}_{5} / \mathrm{ha} / \mathrm{năm}$.

Bảng 6. Hàm lượng dinh dưỡng trong lá sau thí nghiệm tại huyện Tân Phú Đông, tỉnh Tiền Giang

\begin{tabular}{cccccccccc}
\hline \multirow{2}{*}{ Chỉ tiêu } & \multirow{2}{*}{ Đơn vị } & \multicolumn{7}{c}{ Nghiệm thức (số lần bón/liều lượng phân lân)(\#) } \\
\cline { 3 - 9 } & $2 / 30$ & $2 / 45$ & $2 / 60$ & $2 / 75$ & $4 / 30$ & $4 / 45$ & $4 / 60$ & $4 / 75$ \\
\hline $\mathrm{N}$ & $\%$ & 1,65 & 1,7 & 1,76 & 1,71 & 1,7 & 1,77 & 1,83 & 1,74 \\
$\mathrm{P}$ & $\mathrm{mg} / \mathrm{kg}$ & 1.204 & 1.239 & 1.269 & 1.260 & 1.248 & 1.275 & 1.293 & 1.270 \\
$\mathrm{~K}$ & $\%$ & 0,98 & 1,03 & 1,04 & 1,00 & 1,06 & 1,13 & 1,13 & 1,01 \\
\hline (\#) Sồ lần bón: lần/năm; liều lượng phân lân: $\mathrm{kg}_{2} \mathrm{O}_{5} / \mathrm{ha} /$ năm.
\end{tabular}

Tre và 0,47 đến 0,50 tại Tiền Giang. Bên cạnh đó, Ec trong dung dịch đất tăng lên so với trước thí nghiệm cho thấy tổng nồng độ ion hòa tan trong dung dịch đất được cải thiện, tạo điều kiện cho cây dừa hấp thụ các chất dinh dưỡng được dễ dàng, đồng thời giúp cho cây tăng khả năng chống chịu trong điều kiện xâm nhập mặn.

Sau thí nghiệm, hàm lượng dinh dưỡng trong lá được trình bày ở Bảng 5 và Bảng 6 .

Sự gia tăng hàm lượng dinh dưỡng trong đất tác động đến sự hấp thu dinh dưỡng của lá và hàm lượng dinh dưỡng trong lá đều tăng hơn so với trước thí nghiệm (Bảng 5 và Bảng 6 ). Các nghiệm thức tại Bến Tre dao động từ 805 đến 858 $\mathrm{mg} / \mathrm{kg}$, tại Tiền Giang từ 1.204 đến $1.293 \mathrm{mg} / \mathrm{kg}$. Theo Nampoothiri \& ctv. (2018), hàm lượng lân tối ưu trong lá dừa là 1.200 đến $1.300 \mathrm{mg} / \mathrm{kg}$ mới đáp ứng nhu cầu của cây dừa, vì thế tại Bến Tre chưa đáp ứng đủ được ngưỡng tối ưu. Điều này thể hiện rõ trong điều kiện độ mặn cao ảnh hưởng 
Bảng 7. Ảnh hưởng của số lần bón và liều lượng phân lân đến tổng số lá mọc thêm (lá/cây) sau 12 tháng thí nghiệm của cây dừa Ta 6 năm tuổi tại Bến Tre và Tiền Giang

\begin{tabular}{|c|c|c|c|c|c|c|}
\hline \multirow{3}{*}{$\begin{array}{c}\text { Liều lượng } \\
\left(\mathrm{kg} \mathrm{P}_{2} \mathrm{O}_{5} / \mathrm{ha}\right) \\
\text { (B) }\end{array}$} & \multicolumn{3}{|c|}{ Bến Tre } & \multicolumn{3}{|c|}{ Tiền Giang } \\
\hline & \multicolumn{2}{|c|}{ Số lần bón/năm (A) } & \multirow{2}{*}{ TB } & \multicolumn{2}{|c|}{ Số lần bón/năm (A) } & \multirow{2}{*}{ TB } \\
\hline & 2 & 4 & & 2 & 4 & \\
\hline 30 & $12,8^{\mathrm{b}}$ & $12,7^{\mathrm{bc}}$ & $12,7^{\mathrm{c}^{\prime}}$ & $12,9^{\mathrm{c}}$ & $13,5^{\mathrm{bc}}$ & $13,2^{\mathrm{b}^{\prime}}$ \\
\hline 45 & $12,8^{\mathrm{bc}}$ & $13,3^{\mathrm{b}}$ & $13,0^{\mathrm{b}^{\prime}}$ & $13,5^{\mathrm{bc}}$ & $14,0^{\mathrm{b}}$ & $13,7^{\mathrm{a}^{\prime} \mathrm{b}^{\prime}}$ \\
\hline 60 & $13,1^{\mathrm{b}}$ & $14,7^{\mathrm{a}}$ & $13,9^{\mathrm{a}^{\prime}}$ & $13,1^{\mathrm{c}}$ & $14,8^{\mathrm{a}}$ & $14,0^{\mathrm{a}^{\prime}}$ \\
\hline 75 & $12,7^{\mathrm{c}}$ & $13,4^{\mathrm{b}}$ & $13,1^{\mathrm{b}^{\prime}}$ & $11,8^{\mathrm{d}}$ & $13,5^{\mathrm{bc}}$ & $12,6^{\mathrm{b}^{\prime}}$ \\
\hline \multirow[t]{2}{*}{ TB } & $12,8^{b}$ & $13,5^{\mathrm{a}}$ & & $12,8^{\mathrm{b}}$ & $13,9^{\mathrm{a}}$ & \\
\hline & $\begin{array}{c}\mathrm{CV}_{\mathrm{b}}( \\
\mathrm{F}_{\mathrm{B}}\end{array}$ & $\begin{array}{l}=4,10 \mathrm{~F}_{\mathrm{A}} \\
72^{* *} \mathrm{~F}_{\mathrm{AB}}\end{array}$ & $\begin{array}{l}13,42^{* *} \\
3,49^{*}\end{array}$ & $\begin{array}{r}\mathrm{CV}_{\mathrm{b}} \\
\mathrm{F}_{\mathrm{B}}=\end{array}$ & $\begin{array}{l}=3,35 \mathrm{~F}_{\mathrm{A}} \\
, 31^{* *} \mathrm{~F}_{\mathrm{AB}}\end{array}$ & $\begin{array}{l}=19,22^{*} \\
=3,51^{*}\end{array}$ \\
\hline
\end{tabular}

$\overline{\mathrm{a}-\mathrm{d}},{ }^{a^{\prime}-b^{\prime}}$ Trong cùng một hàng hoặc một cột, các trung bình mang các chữ cái khác nhau chỉ sự khác biệt có ý nghĩa thống kề $(P<0,05)$; NS: khác biệt không có ý nghĩa thống kê.

*: Khác biệt có ý nghĩa thống kê ở $\alpha=0,05$; **: khác biệt có ý nghĩa thống kê ở $\alpha=0,01$.

Bảng 8. Ảnh hưởng của số lần bón và liều lượng phân lân đến chiều dài phần mang lá của lá chức năng $(\mathrm{cm})$ của cây dừa Ta 6 năm tuổi tại Bến Tre và Tiền Giang

\begin{tabular}{ccccccc}
\hline $\begin{array}{c}\text { Liều lượng } \\
\left(\mathrm{kg} \mathrm{P} \mathrm{P}_{2} \mathrm{O}_{5} / \mathrm{ha}\right)\end{array}$ & \multicolumn{3}{c}{ Bến Tre } & \multicolumn{3}{c}{ Tiền Giang } \\
\cline { 2 - 3 }$(\mathrm{B})$ & \multicolumn{2}{c}{ Số lần bón/năm $(\mathrm{A})$} & \multirow{2}{*}{$\mathrm{TB}$} & \multicolumn{2}{c}{ Số lần bón/năm $(\mathrm{A})$} & \multirow{2}{*}{$\mathrm{TB}$} \\
\cline { 2 - 3 } \cline { 5 - 6 } & 327,5 & 315,5 & 321,5 & 345,2 & 349,3 & 345,6 \\
45 & 315,8 & 316,2 & 316,0 & 330,7 & 331,8 & 331,3 \\
60 & 313,7 & 322,3 & 318,0 & 329,0 & 348,5 & 338,8 \\
75 & 303,2 & 326,3 & 314,8 & 326,2 & 348,8 & 337,5 \\
\hline $\mathrm{TB}$ & 315,5 & 320,0 & & 332,8 & 343,8 \\
\hline
\end{tabular}

NS: Khác biệt không có ý nghĩa thống kê.

đáng kể đến sự sinh trưởng và khả năng hấp thu các chất dinh dưỡng của cây dừa (Remison \& ctv., 1988). Trong đó hàm lượng lân trong lá cao nhất ở nghiệm thức bón 4 lần/năm với liều lượng $60 \mathrm{~kg} \mathrm{P}_{2} \mathrm{O}_{5} / \mathrm{ha} /$ năm, điều này cho thấy nghiệm thức bón $60 \mathrm{~kg} \mathrm{P}_{2} \mathrm{O}_{5} /$ ha là phù hợp vì khi tăng lên $75 \mathrm{~kg} \mathrm{P}_{2} \mathrm{O}_{5} /$ ha thì lượng lân trong lá không tăng lên ở cả hai số lần bón dẫn đến hiệu quả sử dụng phân bón thấp hơn.

\section{2. Ảnh hưởng của phân lân đến quá trình sinh trưởng của cây dừa}

Theo dõi quá trình sinh trưởng của cây dừa trong thí nghiệm, kết quả phân tích các chỉ tiêu: số lá mọc thêm/cây, chiều dài phần mang lá của lá chức năng được trình bày ở Bảng 7 và Bảng 8 .

Bảng 7 cho thấy số lá mọc thêm của cây dừa khác biệt có ý nghĩa, trung bình đạt từ 12,7 đến 14,7 lá tại Bến Tre và 11,8 đến 14,8 lá tại Tiền Giang. Tại hai địa điểm cho thấy bón phân 4 lần/năm có số lá mọc thêm cao hơn so với bón 2 lần/năm, liều lượng phân lân ở mức $60 \mathrm{~kg}$ $\mathrm{P}_{2} \mathrm{O}_{5} /$ ha có số lá mọc thêm trung bình cao hơn các liều lượng còn lại. Vì vậy, sự tương tác giữa số lần bón với liều lượng phân lân thể hiện cao nhất ở nghiệm thức bón 4 lần/năm ứng với liều lượng $60 \mathrm{~kg} \mathrm{P}_{2} \mathrm{O}_{5} / \mathrm{ha}$.

Chiều dài phần mang lá của lá chức năng của cây dừa cả hai địa điểm khác biệt không có ý nghĩa, trung bình đạt $317,6 \mathrm{~cm} /$ lá tại Bến Tre và 338,7 cm/lá tại Tiền Giang (Bảng 8).

\section{3. Ảnh hưởng của phân lân đến tỉ lệ đậu trái và năng suất cây dừa}

Bảng 9 cho thấy tỉ lệ đậu trái của các nghiệm thức khác biệt có ý nghĩa. Trong đó Bến Tre tî̉ lệ đậu cao nhất ở nghiệm thức bón phân 4 lần/năm ứng với liều lượng $60 \mathrm{~kg} \mathrm{P}_{2} \mathrm{O}_{5} /$ ha đạt $56,4 \%$, khác biệt có ý nghĩa so với các nghiệm thức còn lại, thấp nhất là nghiệm thức bón 2 lần/năm với liều 
Bảng 9. Ảnh hưởng của số lần bón và liều lượng phân lân đến tỉ lệ đậu trái (\%) của cây dừa Ta 6 năm tuổi tại Bến Tre và Tiền Giang

\begin{tabular}{|c|c|c|c|c|c|c|}
\hline \multirow{3}{*}{$\begin{array}{c}\text { Liều lượng } \\
\left(\mathrm{kg} \mathrm{P}_{2} \mathrm{O}_{5} / \mathrm{ha}\right) \\
\text { (B) }\end{array}$} & \multicolumn{3}{|c|}{ Bến Tre } & \multicolumn{3}{|c|}{ Tiền Giang } \\
\hline & \multicolumn{2}{|c|}{ Số lần bón/năm (A) } & \multirow{2}{*}{ TB } & \multicolumn{2}{|c|}{ Số lần bón/năm (A) } & \multirow{2}{*}{ TB } \\
\hline & 2 & 4 & & 2 & 4 & \\
\hline 30 & $46,5^{\mathrm{e}}$ & $52,4^{\text {bc }}$ & $49,5^{\mathrm{b}^{\prime}}$ & $49,7^{\mathrm{bc}}$ & $50,6^{\mathrm{b}}$ & $50,1^{b^{\prime}}$ \\
\hline 45 & $49,7^{\mathrm{d}}$ & $53,5^{\mathrm{b}}$ & $51,6^{\mathrm{a}^{\prime}}$ & $49,4^{\mathrm{c}}$ & $54,2^{\mathrm{a}}$ & $51,8^{\mathrm{a}^{\prime} \mathrm{b}^{\prime}}$ \\
\hline 60 & $50,0^{\mathrm{d}}$ & $56,4^{\mathrm{a}}$ & $53,1^{\mathrm{a}^{\prime}}$ & $50,2^{\mathrm{b}}$ & $56,6^{\mathrm{a}}$ & $53,4^{\mathrm{a}^{\prime}}$ \\
\hline 75 & $50,7^{\mathrm{cd}}$ & $53,3^{\mathrm{b}}$ & $52,0^{\mathrm{a}^{\prime}}$ & $50,6^{\mathrm{b}}$ & $50,3^{\mathrm{b}}$ & $50,4^{\mathrm{a}^{\prime}}$ \\
\hline \multirow[t]{2}{*}{ TB } & $49,2^{\mathrm{b}}$ & $53,9^{\mathrm{a}}$ & & $50,0^{\mathrm{b}}$ & $52,9^{\mathrm{a}}$ & \\
\hline & $\begin{array}{l}\mathrm{CV}_{\mathrm{b}} \\
\mathrm{F}_{\mathrm{B}}=\end{array}$ & $\begin{array}{l}=2,19 \mathrm{~F}_{\mathrm{A}} \\
19^{* *} \mathrm{~F}_{\mathrm{AB}}\end{array}$ & $\begin{array}{c}61,6^{*} \\
3,90^{*}\end{array}$ & $\begin{array}{r}\mathrm{CV}_{\mathrm{b}} \\
\mathrm{F}_{\mathrm{B}}\end{array}$ & $\begin{array}{l}=3,18 \mathrm{~F}_{\mathrm{A}} \\
01^{*} \mathrm{~F}_{\mathrm{AB}}\end{array}$ & $\begin{array}{l}34,85^{*} \\
5,65^{*}\end{array}$ \\
\hline
\end{tabular}

$\overline{a-d} a^{\prime}-b^{\prime}$ Trong cùng một hàng hoặc một cột, các trung bình mang các chữ cái khác nhau chỉ sự khác biệt có ý nghĩa thống kề $(P<0,05)$; NS: khác biệt không có ý nghĩa thống kê.

*: Khác biệt có ý nghĩa thống kể ở $\alpha=0,05$; **: khác biệt có ý nghĩa thống kê ở $\alpha=0,01$.

Bảng 10. Ảnh hưởng của số lần bón và liều lượng phân lân đến số trái/buồng của cây dừa Ta 6 năm tuổi tại Bến Tre và Tiền Giang

\begin{tabular}{|c|c|c|c|c|c|c|}
\hline \multirow{3}{*}{$\begin{array}{c}\text { Liều lượng } \\
\left(\mathrm{kg} \mathrm{P}_{2} \mathrm{O}_{5} / \mathrm{ha}\right) \\
\text { (B) }\end{array}$} & \multicolumn{3}{|c|}{ Bến Tre } & \multicolumn{3}{|c|}{ Tiền Giang } \\
\hline & \multicolumn{2}{|c|}{ Số lần bón/năm $(\mathrm{A})$} & \multirow{2}{*}{ ТВ } & \multicolumn{2}{|c|}{ Số lần bón/năm $(\mathrm{A})$} & \multirow{2}{*}{ TB } \\
\hline & 2 & 4 & & 2 & 4 & \\
\hline 30 & $3,9^{\mathrm{d}}$ & $4,8^{\mathrm{c}}$ & $4,3^{\mathrm{b}^{\prime}}$ & $4,1^{\mathrm{d}}$ & $4,7^{\mathrm{bc}}$ & $4,4^{\mathrm{b}^{\prime}}$ \\
\hline 45 & $4,1^{\mathrm{cd}}$ & $4,8^{\mathrm{b}}$ & $4,5^{\mathrm{b}^{\prime}}$ & $4,3^{\mathrm{cd}}$ & $4,8^{\mathrm{b}}$ & $4,6^{\mathrm{a}^{\prime} \mathrm{b}^{\prime}}$ \\
\hline 60 & $4,3^{\mathrm{c}}$ & $5,6^{\mathrm{a}}$ & $4,9^{\mathrm{a}^{\prime}}$ & $4,4^{\mathrm{bcd}}$ & $5,4^{\mathrm{a}}$ & $4,9^{\mathrm{a}^{\prime}}$ \\
\hline 75 & $4,4^{\mathrm{c}}$ & $4,9^{\mathrm{b}}$ & $4,7^{\mathrm{a}^{\prime} \mathrm{b}^{\prime}}$ & $4,5^{\mathrm{bc}}$ & $4,7^{\mathrm{bc}}$ & $4,6^{\mathrm{a}^{\prime} \mathrm{b}^{\prime}}$ \\
\hline \multirow[t]{2}{*}{ TB } & $4,2^{\mathrm{b}}$ & $5,0^{\mathrm{a}}$ & & $4,3^{\mathrm{b}}$ & $4,9^{\mathrm{a}}$ & \\
\hline & \multicolumn{3}{|c|}{$\begin{array}{c}\mathrm{CV}_{\mathrm{b}}(\%)=4,07 \mathrm{~F}_{\mathrm{A}}=37,5^{* *} \\
\mathrm{~F}_{\mathrm{B}}=13,2^{* *} \mathrm{~F}_{\mathrm{AB}}=4,00^{*}\end{array}$} & \multicolumn{3}{|c|}{$\begin{array}{c}\mathrm{CV}_{\mathrm{b}}(\%)=4,46 \mathrm{~F}_{\mathrm{A}}=20,69^{*} \\
\mathrm{~F}_{\mathrm{B}}=6,65^{* *} \mathrm{~F}_{\mathrm{AB}}=4,51^{*}\end{array}$} \\
\hline
\end{tabular}

$\overline{\mathrm{a}-\mathrm{d}},{ }^{a^{\prime}-b^{\prime}}$ Trong cùng một hàng hoặc một cột, các trung bình mang các chữ cái khác nhau chỉ sự khác biệt có ý nghĩa thống kề $(P<0,05)$; NS: khác biệt không có ý nghĩa thống kê.

*: Khác biệt có ý nghĩa thống kê ở $\alpha=0,05$; **: khác biệt có ý nghĩa thống kể ở $\alpha=0,01$.

lượng $30 \mathrm{~kg} \mathrm{P}_{2} \mathrm{O}_{5} /$ ha. Tại Tiền Giang, tỉ lệ đậu trái tương đối cao hơn, cao nhất cũng ở nghiệm thức bón phân 4 lần/năm ứng với liều lượng $60 \mathrm{~kg}$ $\mathrm{P}_{2} \mathrm{O}_{5} /$ ha đạt $56,6 \%$, khác biệt có ý nghĩa thống kê so với nghiệm thức bón 2 lần/năm ứng với 30 $\mathrm{kg} \mathrm{P}_{2} \mathrm{O}_{5} /$ ha là $49,7 \%$ (Bảng 9 ).

Về năng suất, bón phân lân cũng đã cho hiệu quả rõ rệt đến số trái/buồng và số trái/7 tháng.

Bảng 10 cho thấy Bến Tre và Tiền Giang, số trái/buồng đạt cao nhất lần lượt là 5,6 trái và 5,4 trái của nghiệm thức bón phân 4 lần/năm ứng với

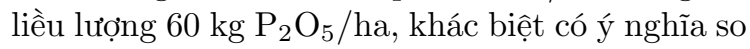
với các nghiệm thức còn lại. Do ảnh hưởng của độ mặn trong nước cao từ cuối năm 2019 dến giữa năm 2020 (Hình 1) nên số trái/buồng thấp hơn so với cây dừa trong điều kiện bình thường ở năm thứ 6 là khoảng $6-7$ trái/buồng (Pham \& ctv., 2010).

Năng suất cây dừa khác biệt có ý nghĩa thống kê giữa số lần bón/năm, liều lượng phân lân/năm và các nghiệm thức phối hợp tại Bến Tre và Tiền Giang. Trong đó, cao nhất là nghiệm thức bón phân 4 lần/năm ứng với liều lượng $60 \mathrm{~kg}$ $\mathrm{P}_{2} \mathrm{O}_{5} /$ ha, đạt 35,0 trái tại Bến Tre và 36,8 trái tại Tiền Giang (Bảng 11). Trong điều kiện độ mặn cao ảnh hưởng đến quá trình hình thành phát hoa, thụ phấn và thụ tinh nên có số trái thấp hơn so với điều kiện tối ưu (Thai \& ctv., 2018). Tuy nhiên, bón phân cân đối và cung cấp đủ hàm lượng dinh dưỡng cho cây dừa giúp cải thiện được số trái và năng suất, đồng thời tăng khả năng chống chịu của cây dừa đối với điều kiện bất lợi (Thai \& ctv., 2020). Kết quả này cũng phù hợp với nghiên cứu của Loganathan \& Balakrishnamurti (1980) cho thấy tỉ lệ đậu trái, số trái/buồng và năng suất được cải thiện khi bón phân lân ở mức $2 \mathrm{~kg}$ super lân/cây/năm (tương ứng $57,6 \mathrm{~kg} \mathrm{P}_{2} \mathrm{O}_{5} / \mathrm{ha}$ ). 
Bảng 11. Ảnh hưởng của số lần bón và liều lượng phân lân đến năng suất thực thu (trái/7 tháng) của cây dừa Ta 6 năm tuổi tính đến thời điểm kết thúc thí nghiệm tại Bến Tre và Tiền Giang

\begin{tabular}{|c|c|c|c|c|c|c|}
\hline \multirow{3}{*}{$\begin{array}{c}\text { Liều lượng } \\
\left(\mathrm{kg} \mathrm{P}_{2} \mathrm{O}_{5} / \mathrm{ha}\right) \\
(\mathrm{B})\end{array}$} & \multicolumn{3}{|c|}{ Bến Tre } & \multicolumn{3}{|c|}{ Tiền Giang } \\
\hline & \multicolumn{2}{|c|}{ Số lần bón/năm $(\mathrm{A})$} & \multirow{2}{*}{ TB } & \multicolumn{2}{|c|}{ Số lần bón/năm (A) } & \multirow{2}{*}{ TB } \\
\hline & 2 & 4 & & 2 & 4 & \\
\hline 30 & $28,7^{\mathrm{d}}$ & $33,3^{\mathrm{ab}}$ & $31,0^{\mathrm{b}^{\prime}}$ & $27,2^{\mathrm{d}}$ & $34,8^{\text {ad }}$ & $31,0^{\mathrm{b}^{\prime}}$ \\
\hline 45 & $30,3^{\mathrm{cd}}$ & $31,7^{\mathrm{bc}}$ & $31,0^{\mathrm{b}^{\prime}}$ & $28,4^{\mathrm{d}}$ & $32,3^{\mathrm{ab}}$ & $30,7^{\mathrm{b}^{\prime}}$ \\
\hline 60 & $31,3^{\mathrm{bc}}$ & $35,0^{\mathrm{a}}$ & $33,2^{\mathrm{a}^{\prime}}$ & $29,3^{\mathrm{cd}}$ & $36,8^{\mathrm{a}}$ & $33,1^{\mathrm{a}^{\prime}}$ \\
\hline 75 & $30,7^{\mathrm{cd}}$ & $30,7^{\mathrm{cd}}$ & $30,7^{\mathrm{b}^{\prime}}$ & $32,5^{\mathrm{bc}}$ & $33,3^{\mathrm{b}}$ & $32,9^{\mathrm{a}^{\prime}}$ \\
\hline \multirow[t]{2}{*}{ TB } & $30,3^{b}$ & $32,7^{\mathrm{a}}$ & & $29,4^{\mathrm{b}}$ & $34,5^{\mathrm{a}}$ & \\
\hline & \multicolumn{3}{|c|}{$\begin{array}{c}\mathrm{CV}_{\mathrm{b}}(\%)=4,26 \mathrm{~F}_{\mathrm{A}}=68,73^{*} \\
\mathrm{~F}_{\mathrm{B}}=4,31^{*} \mathrm{~F}_{\mathrm{AB}}=3,63^{*}\end{array}$} & \multicolumn{3}{|c|}{$\begin{array}{c}\mathrm{CV}_{\mathrm{b}}(\%)=4,20 \mathrm{~F}_{\mathrm{A}}=18,74^{*} \\
\mathrm{~F}_{\mathrm{B}}=5,07^{*} \mathrm{~F}_{\mathrm{AB}}=8,57^{* *}\end{array}$} \\
\hline
\end{tabular}

$\overline{\mathrm{a}-\mathrm{d}}, a^{\prime}-b^{\prime}$ Trong cùng một hàng hoặc một cột, các trung bình mang các chữ cái khác nhau chỉ sự khác biệt có ý nghĩa thống kề $(P<0,05)$; NS: khác biệt không có ý nghĩa thống kê.

*: Khác biệt có ý nghĩa thống kê ở $\alpha=0,05$; **: khác biệt có ý nghĩa thống kê ở $\alpha=0,01$.

Bảng 12. Ảnh hưởng của số lần bón và liều lượng phân lân đến khối lượng trái dừa (g/trái) tại Bến Tre và Tiền Giang

\begin{tabular}{|c|c|c|c|c|c|c|}
\hline \multirow{3}{*}{$\begin{array}{c}\text { Liều lượng } \\
\left(\mathrm{kg} \mathrm{P}_{2} \mathrm{O}_{5} / \mathrm{ha}\right) \\
(\mathrm{B})\end{array}$} & \multicolumn{3}{|c|}{ Bến Tre } & \multicolumn{3}{|c|}{ Tiền Giang } \\
\hline & \multicolumn{2}{|c|}{ Số lần bón/năm (A) } & \multirow{2}{*}{ TB } & \multicolumn{2}{|c|}{ Số lần bón/năm $(\mathrm{A})$} & \multirow{2}{*}{ TB } \\
\hline & 2 & 4 & & 2 & 4 & \\
\hline 30 & $1.223,3$ & $1.222,0$ & $1.222,7$ & $1.211,7$ & $1.233,3$ & $1.222,5$ \\
\hline 45 & $1.216,7$ & $1.172,0$ & 1. & $1.183,3$ & $1.196,7$ & 1.1 \\
\hline 60 & $1.210,0$ & $1.230,0$ & $1.220,0$ & $1.208,3$ & $1.241,7$ & $1.225,0$ \\
\hline 75 & $1.196,0$ & $1.120,0$ & $1.158,0$ & $1.208,3$ & $1.233,3$ & $1.220,8$ \\
\hline \multirow[t]{2}{*}{ TB } & $1.211,5$ & $1.186,0$ & & $\begin{array}{l}1.202,9 \\
\end{array}$ & $1.226,3$ & \\
\hline & \multicolumn{3}{|c|}{$\begin{array}{c}\mathrm{CV}_{\mathrm{b}}(\%)=5,55 \mathrm{~F}_{\mathrm{A}}=1,58^{\mathrm{NS}} \\
\mathrm{F}_{\mathrm{B}}=1,22^{\mathrm{NS}} \mathrm{F}_{\mathrm{AB}}=0,63^{\mathrm{NS}}\end{array}$} & \multicolumn{3}{|c|}{$\begin{array}{c}\mathrm{CV}_{\mathrm{b}}(\%)=5,61 \mathrm{~F}_{\mathrm{A}}=7,14^{\mathrm{NS}} \\
\mathrm{F}_{\mathrm{B}}=0,35^{\mathrm{NS}} \mathrm{F}_{\mathrm{AB}}=0,02^{\mathrm{NS}}\end{array}$} \\
\hline
\end{tabular}

NS: Khác biệt không có ý nghĩa thống kê.

Bảng 13. Ảnh hưởng của số lần bón và liều lượng phân lân đến khối lượng cơm dừa (g/trái) tại Bến Tre và Tiền Giang

\begin{tabular}{|c|c|c|c|c|c|c|}
\hline \multirow{3}{*}{$\begin{array}{c}\text { Liều lượng } \\
\left(\mathrm{kg} \mathrm{P}_{2} \mathrm{O}_{5} / \mathrm{ha}\right) \\
\text { (B) }\end{array}$} & \multicolumn{3}{|c|}{ Bến Tre } & \multicolumn{3}{|c|}{ Tiền Giang } \\
\hline & \multicolumn{2}{|c|}{ Số lần bón/năm $(\mathrm{A})$} & \multirow{2}{*}{ TB } & \multicolumn{2}{|c|}{ Số lần bón/năm (A) } & \multirow{2}{*}{ TB } \\
\hline & 2 & 4 & & 2 & 4 & \\
\hline 30 & $\overline{225,0}$ & 223,3 & 224,2 & 245,0 & 250,3 & 248,8 \\
\hline 45 & 217,0 & 223,5 & 220,3 & 240,0 & 254,7 & 247,3 \\
\hline 60 & 229,0 & 233,3 & 227,5 & 231,2 & 253,3 & 242,5 \\
\hline 75 & 226,7 & 215,0 & 220,8 & 235,0 & 243,3 & 239,2 \\
\hline \multirow[t]{2}{*}{ TB } & 222,6 & 223,8 & & 237,9 & 251,0 & \\
\hline & \multicolumn{3}{|c|}{$\begin{array}{c}\mathrm{CV}_{\mathrm{b}}(\%)=8,29 \mathrm{~F}_{\mathrm{A}}=0,03^{\mathrm{NS}} \\
\mathrm{F}_{\mathrm{B}}=0,20^{\mathrm{NS}} \mathrm{F}_{\mathrm{AB}}=0,46^{\mathrm{NS}}\end{array}$} & \multicolumn{3}{|c|}{$\begin{array}{c}\mathrm{CV}_{\mathrm{b}}(\%)=6,27 \mathrm{~F}_{\mathrm{A}}=4,37^{\mathrm{NS}} \\
\mathrm{F}_{\mathrm{B}}=0,50^{\mathrm{NS}} \mathrm{F}_{\mathrm{AB}}=0,27^{\mathrm{NS}}\end{array}$} \\
\hline
\end{tabular}

NS: Khác biệt không có ý nghĩa thống kê.

\section{4. Ảnh hưởng của phân lân đến chất lượng trái dừa}

Chất lượng trái dừa được đánh giá thông qua các chỉ tiêu: khối lượng trái, khối lượng cơm dừa/trái và hàm lượng dầu. Các số liệu được trình bày ở Bảng 12, Bảng 13 và Bảng 14 .

Chưa thấy có sự sai khác về khối lượng trái, khối lượng cơm và hàm lượng dầu giữa các nghiệm thức riêng lẻ và phối hợp, qua đó cho thấy ảnh hưởng của phân lân đến chất lượng trái dừa chưa đáng kể, trong đó tại Bến Tre có khối 
Bảng 14. Ảnh hưởng của số lần bón và liều lượng phân lân đến hàm lượng dầu dừa (\%) tại Bến Tre và Tiền Giang

\begin{tabular}{ccccc}
\hline \multirow{2}{*}{ Nghiệm thức (\#) } & \multicolumn{2}{c}{ Bến Tre } & \multicolumn{2}{c}{ Tiền Giang } \\
\cline { 2 - 5 } & Hàm lượng dầu $(\%)$ & Độ ẩm (\%) & Hàm lượng dầu (\%) & Độ ẩm (\%) \\
\hline $2 / 30$ & 64,3 & 58,3 & 59,8 & 59,4 \\
$2 / 45$ & 64,1 & 58,2 & 59,6 & 59,4 \\
$2 / 60$ & 64,4 & 57,5 & 59,7 & 60,7 \\
$2 / 75$ & 64,4 & 57,8 & 59,8 & 59,3 \\
$4 / 30$ & 64,5 & 58,4 & 59,8 & 61,4 \\
$4 / 45$ & 64,6 & 58,6 & 59,8 & 60,0 \\
$4 / 60$ & 64,8 & 58,9 & 59,9 & 61,8 \\
$4 / 75$ & 64,6 & 57,0 & 59,8 & 60,0 \\
\hline
\end{tabular}

(\#) Số lần bón: lần/năm; liều lượng phân lân: $\mathrm{kg} \mathrm{P}_{2} \mathrm{O}_{5} / \mathrm{ha} / \mathrm{năm}$.

lượng trái dao động từ 1.172,0 đến 1.230,0 g/trái và khối lượng cơm dao động từ 215,0 đến 233,3 $\mathrm{g} /$ trái, tương ứng tại Tiền Giang là 1.183,3 đến $1.233,3 \mathrm{~g} /$ trái và 231,0 đến $254,7 \mathrm{~g} /$ trái. Độ mặn cao tác động đến sự hình thành trái nên ở vùng nhiễm mặn, khối lượng trái và khối lượng cơm thấp hơn so với điều kiện bình thường (Thai \& ctv., 2015). Hàm lượng dầu của trái dừa Ta tại Bến Tre dao động từ $64,1 \%$ dến $64,8 \%$ và tại Tiền Giang từ $59,6 \%$ đến $59,9 \%$, điều này phù hợp với các nghiên cứu trước đây cho thấy hàm lượng dầu biến động tùy theo giống, điều kiện sinh thái và chế độ chăm sóc (Pham \& ctv., 2010).

\section{Kết Luận}

Trong điều kiện xâm nhập mặn cao nhất vào mùa khô với độ mặn của nước trong mương vườn dừa là 13,8\%o tại Bến Tre và 6,3\%o tại Tiền Giang, bón phân lân 4 lần/năm với mức $60 \mathrm{~kg}$ $\mathrm{P}_{2} \mathrm{O}_{5} /$ ha có hàm lượng lân dễ tiêu trong đất tăng lên tác động đến sự hấp thu dinh dưỡng của cây, cải thiện hàm lượng dinh dưỡng trong lá, thúc đẩy sinh trưởng và phát triển của cây dừa. Cây dừa ở nghiệm thức bón phân 4 lần/năm với mức $60 \mathrm{~kg} \mathrm{P}_{2} \mathrm{O}_{5} /$ ha có tổng số lá mọc thêm, tỉ lệ đậu trái, số trái/buồng và năng suất trái cao hơn so với các nghiệm thức còn lại.

\section{Lời Cảm Ơn}

Nghiên cứu đã được thực hiện dưới sự hỗ trợ kinh phí của Bộ Công Thương trong phạm vi đề tài "Nghiên cứu chọn tạo giống dừa cho các tỉnh phía Nam" giai đoạn 2019 - 2023 do Viện Nghiên Cứu Dầu và Cây Có Dầu chủ trì.

\section{Tài Liệu Tham Khảo (References)}

BTSO (Ben Tre Statistic Office). (2018). Report for social and economic situation in the first ten months in 2018 in Ben Tre province. Report No. 588BC-CTK dated October 25, 2018. Ben Tre, Vietnam: BTSO.

Cheng-Xu, S., Hong xing, C., Hong bo, S., Xin tao, L., \& Yong, X. (2011). Growth and physiological response to water and nutrient stress in oil palm. African Journal of Biotechnology 10(51), 10465-10471.

FAO (The Food and Agriculture Organization). (2020). Area harvested and production quantity of coconut. Retrieved August 1, 2020, from http://www.fao.org/faostat/en/\#data/QC.

IRHO (Research Institute for Oil and Oil Plants). (1992). Coconut - Study of yield factors. Paris, France: IRHO.

Loganathan, P., \& Balakrishnamurti, T. (1980). Effects of NPK fertilizers on young coconut (Cocos nucifera L.) in Sri Lanka. Experimental Agriculture 16(1), 41-48.

Nampoothiri, K. U. K., Krishnakumar, V., Thampan, P. K., \& Nair, M. A. (2018). The coconut palm (Cocos nucifera L.) - Research and development perspectives. Singapore: Springer.

Nguyen, V. B., Tran, H. V., \& Le, P. T. (2005). Perennial crops, part II industrial crops. Can Tho, Vietnam: Can Tho University Publishing House.

Pham, L. T., Vo, L. V., Nguyen, H. T. B., Luu, T. Q., \& Pham, T. P. (2010). The perfect research on scientific data of four indigenous coconut varieties to apply for seed recognition. Ho Chi Minh City, Vietnam: Research Institute for Oil and Oil Plants.

Remison, U. S., Iremiren, G. O., \& Thomas, G. O. (1988). Effect of salinity on nutrient content of the leaves of coconut seedlings. Plant and Soil 109(1), 135-138.

Santos, G. A., Batugal, P. A., Othman, A., Baudouin, L., \& Labouisse, J. P. (1996). Manual on standardized research techniques in coconut breeding. Singapore: International Coconut Genetic Resources Network. 
Thai, T. N. Q., Luu, T. Q., Pham, T. P., Nguyen, P. T. M., Nguyen, H. T. B., Nguyen, T. D. H., \& Ngo, D. T. K. (2018). The adaptive studies of coconut to saline intrusion conditions (2016 - 2018). Ho Chi Minh City, Vietnam: Research Institute for Oil and Oil Plants.

Thai, T. N. Q., Luu, T. Q., Pham, T. P., Nguyen, P. T. M., Nguyen, T. D. H., \& Nguyen, H. T. B. (2020). Effects of fertilizer on growth, development and yield of coconut under saline intrusion conditions in the Mekong Delta. Vietnam Trade and Industry Review, $38-40$.

Thai, T. N. Q., Ngo, D. T. K., Nguyen, H. T. B., Luu, T. Q., Pham, T. P., \& Nguyen, P. T. M. (2015). The adaptive studies of coconut to saline intrusion conditions (2013 - 2015). Ho Chi Minh City, Vietnam: Research Institute for Oil and Oil Plants.
Ton, T. T. (1974). Improving the coconut industry in Vietnam. Ha Noi, Vietnam: The Agricultural Publishing House.

Tran, H. V., \& Nguyen, L. C. (2011). Investigating flowering characteristics of some tall coconut cultivars (Cocos nucifera L.) in Giong Trom district, Ben Tre provine. Can Tho University Journal of Science 17(a), 210-218.

Tran, H. V., \& Trieu, Q. D. (2011). Survey of factors in ralation to yield, 'fruitless phenomenon' and cultivation method testing on 'Ta Xanh' coconut in Ben Tre province. Can Tho University Journal of Science 17(b), 272-281. 